Indexed by

\title{
DEVELOPMENT OF EQUIPMENT MANAGEMENT SYSTEM WITH MONITORING OF WORKING CHARACTERISTICS OF TECHNOLOGICAL PROCESSES
}

Crossref

KORSON

Boogle

\section{Maria Belousova}

K.G. Razumovsky Moscow State University of technologies and management (the First Cossack University),

Department of Automated Control Systems,

Moscow, Russia

\section{Malvina Karabasheva}

Financial University under the Government of the Russian Federation, Audit and Corporate Reporting Department, Moscow, Russia

\author{
Roman Aleshko \\ Northern (Arctic) Federal \\ University, Higher School of \\ Information Technology and \\ Automated Systems, \\ Department of Information \\ Systems and Technologies, \\ Arkhangelsk, Russia

Sergey Gorovoy
Kuban State Agrarian University
named after I.T. Trubilin,
Department of Machine Repair
and Materials Science,
Krasnodar, Russia

\author{
Rafina Zakieva \\ Kazan State Power Engineering \\ University, Department of \\ Industrial electronics and \\ lighting engineering, \\ Kazan, Russia

\section{Sultanbek Kozhemov \\ Sechenov First Moscow State Medical University, \\ Department of propaedeutics of dental diseases, \\ Moscow, Russia}

Key words: process control system, monitoring, agent systems, equipment, baklava, management

Cite article:

Maria, B., Roman, A., Rafina, Z., Malvina, K., Sergey, G., \& Sultanbek, K. [2021].Development of equipment management system with monitoring of working characteristics of technological processes. Journal of Applied Engineering Science, 19(1) 186 - 192. DOI:10.5937/jaes0-28855

Online aceess of full paper is available at: www.engineeringscience.rs/browse-issues 


\title{
DEVELOPMENT OF EQUIPMENT MANAGEMENT SYSTEM WITH MONITORING OF WORKING CHARACTERISTICS OF TECHNOLOGICAL PROCESSES
}

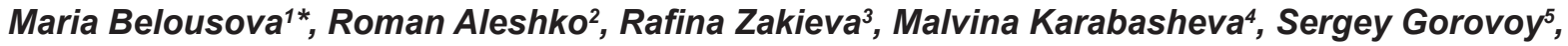 \\ Sultanbek Kozhemov ${ }^{6}$ \\ ${ }^{1}$ K.G. Razumovsky Moscow State University of technologies and management (the First Cossack \\ University), Department of Automated Control Systems, Moscow, Russia \\ ${ }^{2}$ Northern (Arctic) Federal University, Higher School of Information Technology and Automated Systems, \\ Department of Information Systems and Technologies, Arkhangelsk, Russia \\ ${ }^{3}$ Kazan State Power Engineering University, Department of Industrial electronics and lighting engineering, \\ Kazan, Russia \\ ${ }^{4}$ Financial University under the Government of the Russian Federation, Audit and Corporate Reporting \\ Department, Moscow, Russia \\ ${ }^{5}$ Kuban State Agrarian University named after I.T. Trubilin, Department of Machine Repair and Materials \\ Science, Krasnodar, Russia \\ ${ }^{6}$ Sechenov First Moscow State Medical University, Department of propaedeutics of dental diseases, \\ Moscow, Russia
}

The work provides multi-purpose optimization of the baklava production process based on technology of agent systems, the intelligent environment of process control systems. The general architecture of the control system intelligent environment with agent technologies for recognizing abnormal situations was developed and adaptive baklava production regulators were synthesized. It allows you to get the specified dynamic characteristics of the control object based on the developed adaptive systems for adjusting the PID controllers, controlling the parameters of the dough, kneading, separation and baking of baklava. The proposed approach to the construction of an automated process control system with an intelligent environment will reduce the variance of fluctuations in energy consumption, increase the production rate of high-quality baklava and reduce the time for re-equipment and technological modes of operation of baklava production lines.

Key words: process control system, monitoring, agent systems, equipment, baklava, management

\section{INTRODUCTION}

Management of maintenance and repair of equipment is one of the most important tasks of managing any enterprise that has technical and technological systems as part of the assets involved in its production activities. The complexity of solving this problem is connected both with problems in the operation of equipment and with personnel management, attracted resources, planning and monitoring the implementation of work to maintain these systems in working condition.

Equipment management systems are designed to organize the operation of certain types of equipment of the executive system, as well as to coordinate their joint functioning $[3 ; 8 ; 6]$.

Management is based on the use of the modular principle. The main modules are software-controlled equipment. Functionally, a program-controlled module is divided into a control machine and a control object. A program is loaded into the control machine, which it converts into a sequence of control actions transmitted via communication channels. The control object, which can be, for example, a machine, fulfills control actions by performing the corresponding work operations $[14 ; 21 ; 16 ; 17 ; 20]$.
The current state of the control object is characterized by the values of the feedback signals generated by the sensors and fed into the control machine. Due to the presence of feedback, the control machine can form or adjust the sequence of actions in accordance with the current state of the control object. For example, it may be allowed to perform the next work step after receiving a signal from the sensor about the completion of the previous operation, or the appropriate branch of the program after receiving a signal from the sensor about the need to change the sequence of actions according to the results of monitoring the processing object $[11 ; 13]$.

\section{METHODS}

The analysis of the well-known baklava production technologies has led to the conclusion that such production is a typical, non-linear, multi-level process of the food industry. For this production, the implementation of intelligent control programs and its robotization is related to the development of performance monitoring technologies and diagnostics of technological equipment based on agent systems [15] with adaptive control and product quality control [19]. 
The development of adaptive control systems was carried out by M.M. Blagoveshchenskaya [2], I.G. Blagoveshchensky [3], A.V. Tatarinov [19], Gdansky N.I. [7], Popovich A.E. [7], A. Goncharov [10], Budnik A.A. [10]. In their works, it was proved that due to the introduction of process control systems, the initial indicators are significantly improved. At the same time, for the production of healthy foods, it is necessary to add factors of intellectual control to the food industry enterprise with contours for monitoring the quality and performance of equipment based on agent systems. This allows to produce products with innovative features. So, the development of intelligent control systems and monitoring of technological equipment and the quality of raw materials and products based on agent systems for the effective management of non-stationary objects is an urgent scientific task [9; $1 ; 18]$.

Objective. Improving the efficiency of baklava production management by using systems for monitoring the performance of technological equipment and adaptive management based on the intelligent environment of process control systems.

\section{RESULT}

Consider a baklava production line. The baklava production line, starting from loading flour to obtaining finished products, is a complex dynamic system with time-distributed control parameters; characterized by a delay of 9-10 hours, and therefore, is the object of research from the standpoint of developing robot technology equipment, performance monitoring systems and the introduction of energy-efficient manufacturing technologies.

Modern systems of automated control, monitoring and diagnostics of baklava production processes are complex, dynamic, multi-level systems in which knowledge about the fuzzy characteristics of the control object and the environment (in which the enterprise operates) is formed in the process of training and adaptation [2; 3; 12].

The current baklava production lines consist of $n$ elementary technological operations in which the decision maker (DM) interacts with operators and expert systems for supporting optimal decisions.

The multi-purpose optimization of the baklava production process is written as follows (1):

$$
\left\{\begin{array}{l}
P_{\text {production }}\left(x_{i}, y_{i}\right) \rightarrow \max \\
W_{e}\left(x_{i}, y_{i}\right) \rightarrow \text { min } \\
Q_{\text {baklava }}\left(x_{i}, y_{i}\right) \rightarrow \text { optim }
\end{array}\right\}
$$

under restrictions (2):

$$
\left\{\begin{array}{l}
x_{i \min } \leq x_{i} \leq x_{i \max } \\
y_{i \min } \leq y_{i} \leq y_{i \max }
\end{array}\right\}
$$

where $x_{i \min } \ldots, x_{i \max }$ and $y_{i \min } \ldots, y_{i \max }$ - ranges of changes in the operating characteristics of machines and apparatuses and parameters of the baklava production process (balance restrictions); $y_{i}\left(x_{i}\right)$ - functionals that reflect the relationship of the parameters of technological processes of baklava production (Structural constraints); $\mathrm{W}_{\mathrm{e}}\left(\mathrm{x}_{\mathrm{i}}\right.$, $y_{i}$ ) - energy parameters of production of one ton of products; $Q_{\text {baklava }}$ - the quality of baklava is compliant with sugar standards.

In the conditions of fuzzy optimization, it is necessary to monitor both the performance of the equipment and the quality of raw materials, water, dough, and components. Monitoring the performance of equipment, water quality, raw materials and dough allows the decision maker to use the information for: analysis of the reliability of instantaneous values and the removal of unreliable parameters from the database (DB); accumulation of values of design parameters characterizing the state of equipment and its operating characteristics for further averaging and trend analysis of these parameters; averaging the values of each parameter (first per minute, then per hour); forecasting for specific periods of time $T_{1}$, $T_{2}, \ldots, T_{n}$ of values of quality parameters for dough and energy consumption.

In the overall architecture of the intellectual environment, an important role is played by:

- local systems;

- intellectual information systems;

- technology expert assessment and decision support decision maker;

- $\quad$ systems for diagnosing equipment and technological performance;

- $\quad$ systems for recognition, diagnosis and development of abnormal situations.

In the process of analyzing the current state of the control object (CO) and constructing a model of operational activity, a database (DB), a knowledge base (KB) and expert decision support systems (EDSS) are created.

The intelligent environment includes the operational level, hardware, operating systems and objects for monitoring performance and baklava production management. The intelligent environment of the process control system interacts with on-line user agent. When constructing the intelligent environment of the process control system, a number of theoretical concepts of agent technologies developed by the authors were used [19; 15].

Let us consider in more detail the basic concepts of agent theory for the implementation of monitoring processes of complex technological processes of baklava production, the quality of incoming raw materials and finished products. When implementing monitoring systems, it is necessary to take into account the following: technological processes of automated baklava production are a number of sequential operations with heterogeneous characteristics distributed in space.

In fig. 1 shows the general structure of the intellectual 
environment of process control systems for the production of baklava.

The system for monitoring the performance of the equipment of technological lines for the production of baklava is based on the neural network model. It can work both in real time (on-line) and in recording mode (off-line). The developed model for the decision maker (DM) is based on the neural network of direct dissemination of information [22].

The purpose of real-time monitoring of equipment performance is to identify normal/abnormal (emergency) modes of operation of the equipment of the enterprise in the production of baklava.

Based on the number of implementations that were correctly predicted by the neural network, the decision maker can conclude whether the current behavior of the equipment of the baklava production line corresponds to the earlier constructed model. It should be borne in mind that in the process of production over time, equipment changes its operating characteristics, and therefore, in order to ensure adaptation to changes, it is necessary to constantly train the neural network.
Current monitoring is designed to identify uncharacteristic signs of the quality of raw materials and equipment; for example, for raw materials - a change in the variety of wheat flour, a change in the characteristics of water, gas pressure, and the like. We will use this information to build and train a neural network, which is $30-50$ iterations, and the training time is $10 \mathrm{~s}$.

The output of a neural network is determined by the ratio: $y_{i}=f\left(C_{i}, O_{i}, h_{i}, d_{i}, S_{i}\right)$

where $i$ is a conditional session number, $f$ is a nonlinear transformation that is performed by a neural network according to the formulas (1), (2) $C_{-}$- the number of changes in the parameters of flour per day; $O_{-}$-interactive model results (percentage of correctly predicted parameters) $h_{i}-$ equipment number; $d_{i}$-control result; $S_{i}$-control start time. At the same time, the expected output $d_{i}$ can take two values: 1-normal condition of equipment (raw materials); 0 - abnormal characteristic of equipment (raw materials). In this case, the neural network acts as a classifier. Consider the principle of operation of a baklava production monitoring system. It consists of the following components:

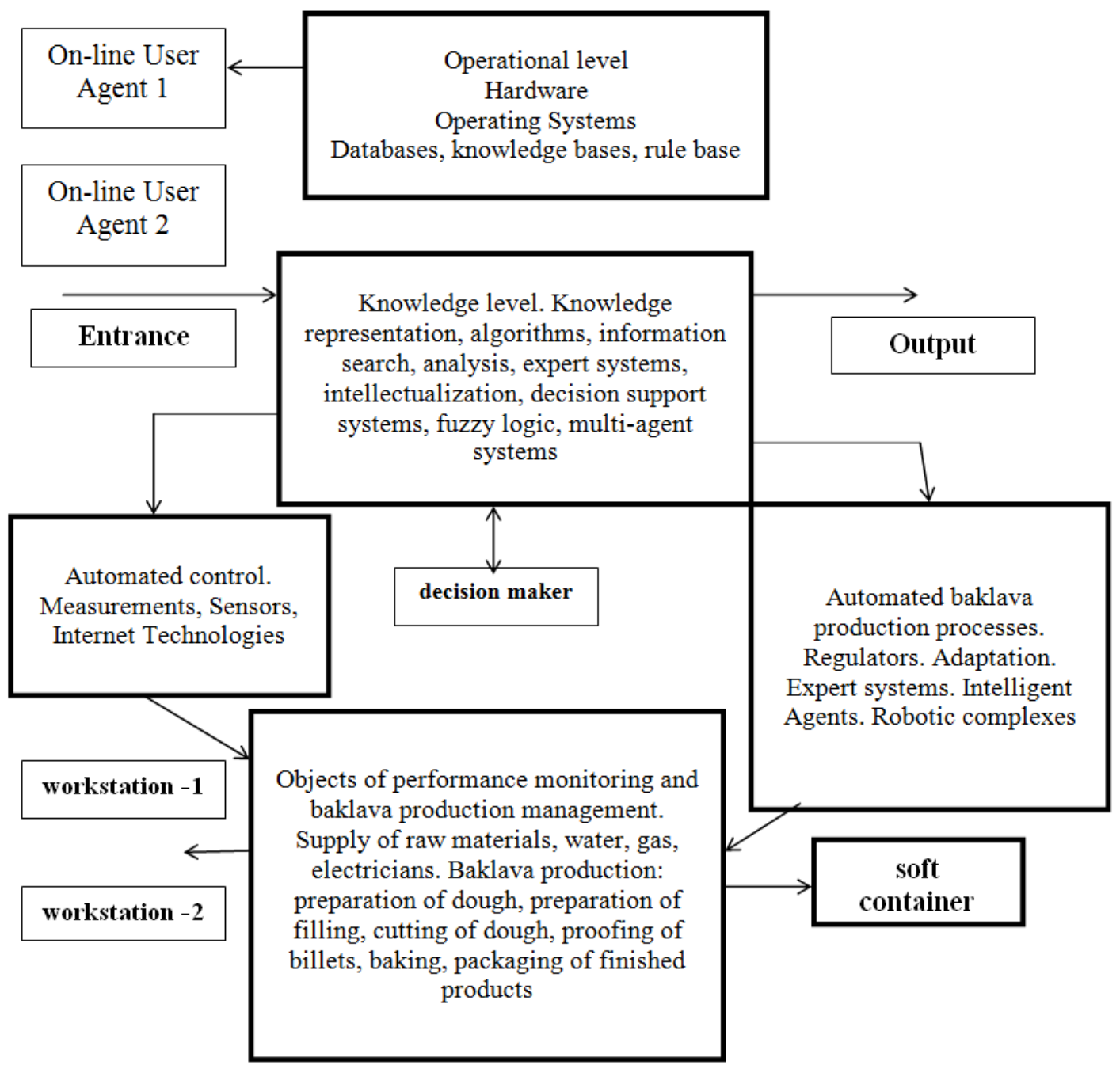

Figure 1: The general structure of the intellectual environment of process control systems for the production of baklava (Source: Author) 
- Agent 1 with an interactive model of equipment operating in real time;

- Agent 2 with a session model for assessing the quality of raw materials, water, energy, which works offline (Off-line User Agent);

- Agent 3-controller, which controls the work of other agents in the system;

- A database that contains data and parameters of existing models.

The process control system for the production of baklava, using SCADA systems, has the means of receiving information from manual input devices and computers of the upper control level. This allows operators to enter the necessary data from automated workstation consoles (AWS), which until now cannot be obtained using automatic sensors or visualization and recognition devices. For example, laboratory tests of flour, water to determine lead, cadmium, arsenic, microtoxins, etc. can be determined in a chemical laboratory and transferred to a computer in manual mode. Information on expert systems (EDSS) and quality management systems (QMS) is supplied to the robotic complex: preparation of raw materials and preparation of dough, preparation and processing of dough, baking of dough pieces, as well as to a system for identifying the dynamic state of the process of baking dough pieces with an adaptive neural network regulator.

The adaptive regulator changes the settings of the regulators of local automated control systems. A typical circuit of a local system with a neural network controller is shown in Fig. 2.

Automatic control systems for a robotic complex for preparing dough and baking it consist of the following blocks: fuzzy control unit (FCU), PID controller, control object (CO), KBO-knowledge base optimizer, GA-genetic algorithm, $k$ is the PID coefficient of the controller, MS-measurement system, $u$ is the control action of the controller on the control object, $e_{\text {zavd }}$-reference signal, $e_{u}-$ amount of regulation, $\varepsilon$ - control error, $d(t)$ is the delay in the measurement system, $z(t)$ is the external influence of the medium.

The local control systems of the lower level of the process control system are supplemented by systems for monitoring the performance of equipment (SMRHO) and product quality.

Let's consider SMRHO in the general architecture of the intellectual environment of the process control system for the production of baklava.

Agent 1, which determines the interactive performance model, functions under the operating time of machines and devices in real time and allows you to identify deviations from the normal mode of operation of the equipment. In the process of monitoring data (flour moisture and its acidity, dough moisture and its temperature, ripening time, humidity and test temperature, etc.), the agent predicts performance characteristics that are compared with the reference ones. If during the period Tmon the number of predicted operating modes (During a monitoring session) is greater than a predetermined threshold, then we assume that the working state (behavior) of the machine, the apparatus is normal, otherwise - the abnormal mode of operation of the baklava production line. In addition, this agent collects and accumulates information on the operating characteristics of machines and apparatuses using Aglets Software Development Kit (ASDK) [15]. Information is stored in a top-level management database. Agent 2 with a session model functions after the session of the monitoring system has ended.

Based on the information collected by Agent 1, the SM$\mathrm{RHO}$ and the QMS operate in real time. At the same time, agent 2, which works out the session model, determines how deviations of the operating characteristics (parameters) of machines and devices were so abnormal. This is determined by the number from the interval $(0-1)$, which indicates the probability of normal operation of machines and apparatuses.

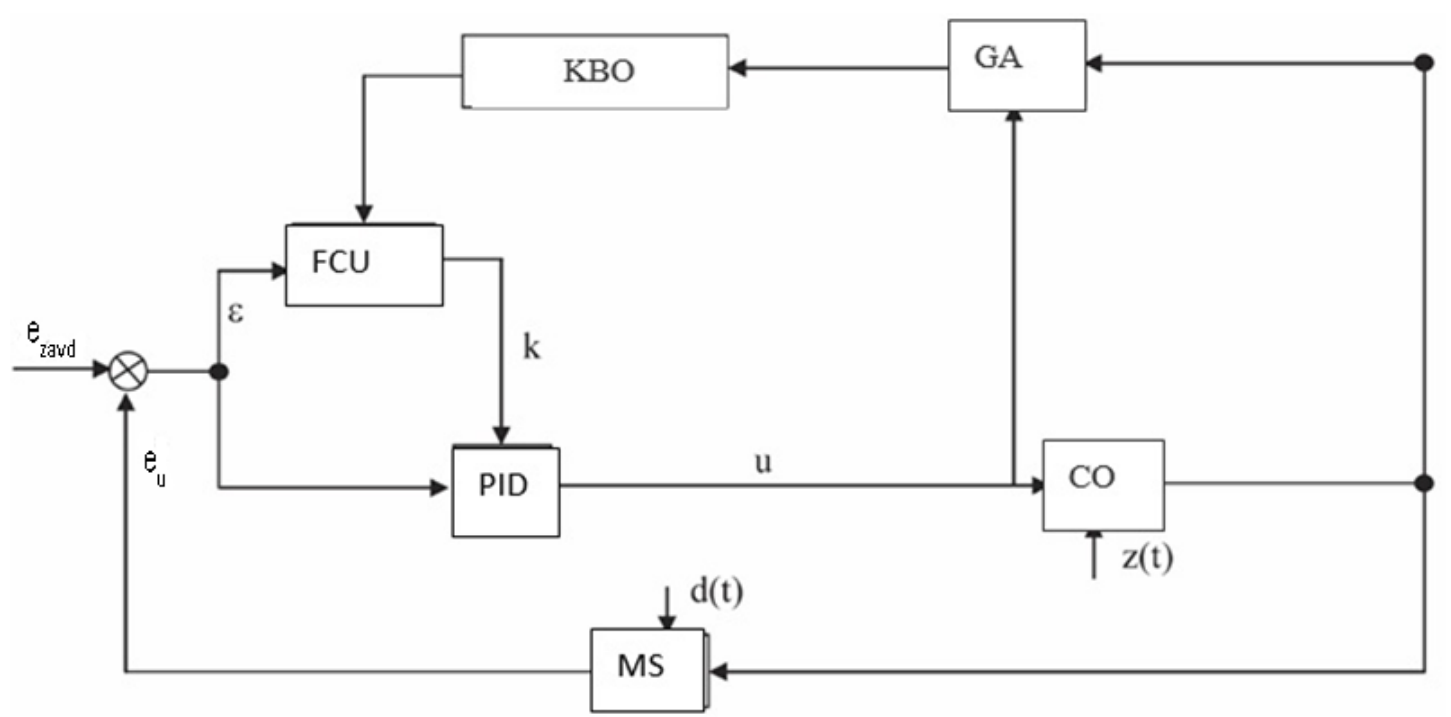

Figure 2: Scheme of a typical adaptive control system for the parameters of dough, kneading, separation and baking of baklava with a neural network controller (Source: Author) 
Agent 3-controller is responsible for the functioning of the system as a whole, controls the work of other agents, the creation of various types of agents. In the process of obtaining information from the database about the model parameters, Agent 2 performs retraining of the neural model. This period of the monitoring process will be called adaptation. Agent 3 receives integrated data on the behavior of all machines and devices. Agent 2 also organizes interaction within the framework of the SM$\mathrm{RHO}$ monitoring system with the process control subsystems, monitors their functioning, and performs communication between agents.

Agent 3 supplements the database with new data on the operating characteristics of machines and apparatuses. So, the database stores the information needed by the enterprise's intelligent control system (ACCS) on the operating characteristics of the technological processes of baklava production, power consumption, water, raw materials, and other components for the functioning and quality control of products. Long-term changes in the operating characteristics of equipment should be taken into account when designing process control systems for baklava factories at the level of local self-propelled guns. So, the systems must adapt at a pace with the process of receipt of flour, yeast, water, other components for making dough, and then the production of baklava. Adaptation is necessary when taking into account long-term and significant changes in the quality parameters of flour, water, yeast, oil, margarine, other components and their deviations from the set quality standards [2; 15].
Based on agent technologies, the authors developed a equipment diagnostic system, which is built on the basis of DiagnoseTools tools. The diagnostic system is shown in Fig. 3.

She performs the following tasks:

- Simovis - diagnostics and evaluation of parametric data of static frequency converters SimovertMasterDrive;

- DIGSI - maintenance, diagnostics, analysis of operational data and factors about cases of equipment failure;

- centralized diagnostics and parametric assessment of the production network;

- parametric evaluation of digital adjustment devices SIMADYN D;

- diagnostics of control devices SIMATIC S7 and studio bus $\mathrm{R}$.

The operator interface of the equipment performance monitoring system interacts with the diagnostic system. In this case, the decision-maker receives information about the development of abnormal situations, equipment failure, deviations of performance beyond the limits of norms. Agent 1 makes a logical conclusion about the cause of the abnormal situations, and Agent 2 makes a logical conclusion about the way to restore the equipment. Agent 3, intellectually interacting with the EDSS, determines the optimal path to restore the equipment's performance.

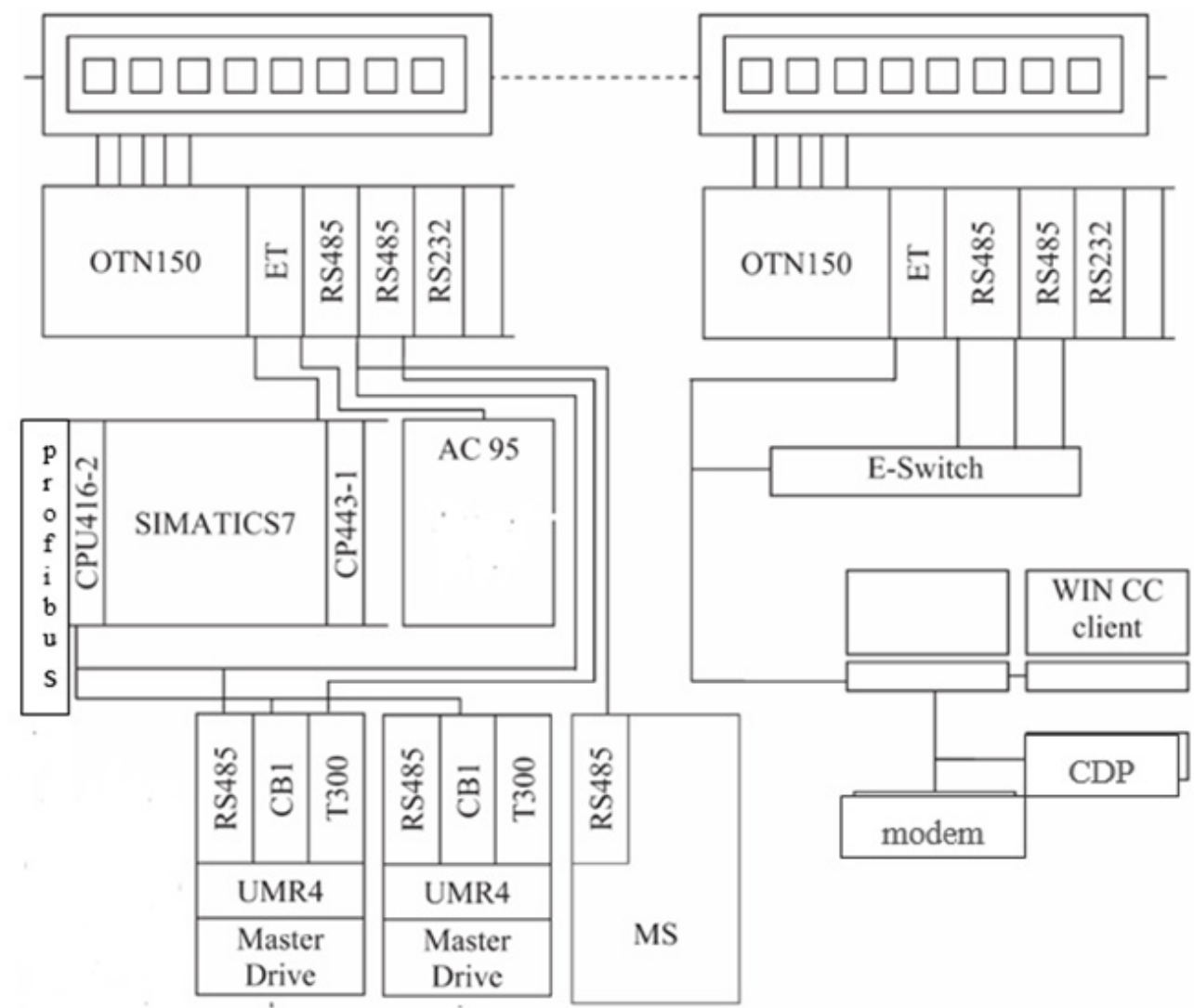

Figure 3. Equipment diagnostic system (Source: [2]) 


\section{CONCLUSION}

Systems for monitoring the performance of equipment and the quality of water, raw materials, dough, and dough are made on the basis of agent technologies, which makes it possible to build robotic control systems for the bakery complex and baklava baking on the basis of adaptive regulators. The general architecture of the control system intelligent environment with agent technologies for recognizing abnormal situations was developed and adaptive baklava production regulators were synthesized. The proposed approach to the construction of an automatic process control system with an intelligent water environment to increase the efficiency of baklava production.

\section{REFERENCES}

1. Almeida, M. V. D. A., Silva, E. M. D., Gomes, N., Nunes, L. A. O., \& Curi, W. F. (2019). Environmental quality of campina grande landfill based on technical and operational aspects. [Qualidade ambiental do aterro sanitario de campina grande com base em aspectos tecnicos e operacionais] Periodico Tche Quimica, 16(32), 77-86.

2. Blagoveshchenskaya, M. M., \& Zlobin L. A. (2005). Information technology of process control systems. M.: Higher School, 768 p.

3. Blagoveshchensky I. G., Nazoykin E. A., Tatarinov A. V. (2017). Fundamentals of creating expertfood quality control systems using intelligent technologies. Food Industry. No 4. [Electronic resource].-Access mode: https://cyberleninka.ru/article/n/osnovy-sozdaniya-ekspertnyh-sistem-kontrolya-kachestva-pischevyh-produktov-s-ispolzovaniem-intellektualnyh-tehnologiy(accessed: 01/18/2020).

4. Cheremisina, O. V., Sergeev, V. V., Chirkst, D. E., \& Litvinova, T. E. (2015). Thermodynamic investigation into extraction of cerium(III) by tributyl phosphate from phosphoric acid solutions. Russian Journal of Non-Ferrous Metals, 56(6), 615-621. http:// doi:10.3103/S1067821215060036

5. Cheremisina, O. V., Sergeev, V. V., Alferova, D. A., \& Ilyna, A. P. (2018). Quantitative x-ray spectral determination of rare-earth metals in products of metallurgy. Paper presented at the Journal of Physics: Conference Series, 1118(1) http://doi:10.1088/1742$6596 / 1118 / 1 / 012012$

6. Chupin, S. A., \& Bolobov, V. I. (2017). The investigation of the influence of thermomechanical treatment of the material of rotary cutter bit toolholders on its hardness. Paper presented at the IOP Conference Series: Materials Science and Engineering, 77(1) http://doi:10.1088/1757-899X/177/1/012062
7. Gdanskii N. I., Popovich A. I., Goncharov A. V., \& Karpov A. V. (2018). Control systems for dynamic processes with single degree of freedom with automatic adaption of the structure and parameters of the system to an external load. Chemical and petroleum engineering. No. 7-8, Vol. 55, pp. 578-589.

8. Gladilina, I. P., Kurbanov, S. A., Maximov, D. A., Dobrova, E. D., \& Dobrova, K. B. (2019). Digital franchising and entrepreneurship: Effects of digital technology on the relations of business process participants. International Journal of Innovative Technology and Exploring Engineering, 9(1), 3892-3896. http://doi:10.35940/ijitee.A4985.119119

9. Grigorev, M. B., Tananykhin, D. S., \& Poroshin, M. A. (2020). Sand management approach for a field with high viscosity oil. Journal of Applied Engineering Science, 2020, vol. 18, br. 1, str. 64-69. http:// doi:10.5937/jaes18-24541

10. Goncharov A.V., Popovich A.E., \& Budnik A.A. (2019). Methods of adaptive and robust control of technological processes: a training manual. $257 \mathrm{p}$.

11. Ivanova, V., Poltarykhin, A., \& Szromnik, A. (2020) State regulation of tariffs in the gas sector. Journal of Security and Sustainability Issues, 9 (3), p. 909-917

12. Kharisova, A. R., \& Puryaev, A. S. (2014). Competitiveness assessment of engineering products. IOP Conference Series: Materials Science and Engineering, 69(1), Article number 012020. http://doi. org/10.1088/1757-899X/69/1/012020

13. Kopteva, A., \& Starshaya, V. (2016). Radioisotope measuring system for oil stream asphaltene-resin-paraffin deposits ARPD parameters. Paper presented at the Society of Petroleum Engineers - SPE Russian Petroleum Technology Conference and Exhibition 2016, 2263-2269.

14. Kozlov, V., Poltarykhin, A., Vasyutkina, L., Ponomarev. V., Filippova, O. \& Popkov, S. (2019). Economic and environmental concept of food development in Russia. Journal of Environmental Management and Tourism, Volume X, Issue 7 (39). Page 1509-1517.

15. Luck, M., McBurney, P., \& Preist, C. (2003). Agent technology: Enabling next generation computing. N. Y., Agent Link, 94 p.

16. Movchan, I. B., \& Yakovleva, A. A. (2019). Refined assessment of seismic microzonation with a priori data optimisation. Journal of Mining Institute, 236, 133-141. http://doi:10.31897/PMI.2019.2.133 
17. Rosa, A. T. R., Pustokhina, I. V., Lydia, E. L., Shankar, K., \& Huda, M. (2019). Concept of electronic document management system (EDMS) as an efficient tool for storing document. Journal of Critical Reviews, 6(5), 85-90. http://doi:10.22159/jcr.06.05.14

18. Rovnik, N. A., Lushpeev, V. A., Tananykhin, D. S., \& Shpurov, I. V. (2020). Rational gas inflow restriction technologies during the development of oil rims. Paper presented at the Topical Issues of Rational use of Natural Resources 2019, 2 888-900. http:// doi:10.1201/9781003014638-54

19. Skakun, S.V., Kussul N.N., Lobunets A.G. (2005). Implementation of a neural network model of computer system users based on agent technology. Problems of control and computer science. №2. - pp. 3-102.

20. Tolfo, F. (1989). An introduction to modular batch automation. Control Engineering. no. 9, vol. 36, p. 216-218.
21. Yumashev, A. V., Koneva, E. S., Borodina, M. A., Lipson, D. U., \& Nedosugova, A. B. (2019). Electronic apps in assessing risk and monitoring of patients with arterial hypertension. Prensa Medica Argentina, 105(4), 235-245.

22. Wooldridge, M. (2002). An introduction to multiagent systems. Chichester, England, John Widey Sons, $366 \mathrm{p}$.

23. Zhukovskyy, V., Zhukovska, N., Vlasyuk, A., \& Safonyk, A. (2019). Method of forensic analysis for compromising carrier-lock algorithm on $3 G$ modem firmware. Paper presented at the 2019 IEEE 2nd Ukraine Conference on Electrical and Computer Engineering, UKRCON 2019 - Proceedings, 11791182. http://doi:10.1109/UKRCON.2019.8879941 